\title{
Learning styles and courseware design
}

Karen Valley

Centre for Studies in Advanced Learning Technology (C SALT), Lancaster University

In this paper we examine how (courseware) can accommodate differences in preferred learning style. $A$ review of the literature on learning styles is followed by a discussion of the implications of being able to accurately classify learners, and key issues that must be addressed are raised. We then present two courseware design solutions that take into account individual learning-style preference: the first follows on from traditional research in this area and assumes that learners can be classified in advance. The second solution takes account of the issues raised previously. We conclude by discussing the feasibility of adapting learning to suit the needs of individual learners, and suggest further research investigating the relationship between preferred learning style and the design of effective interactive learning environments.

\section{Introduction}

As the use of technology to support teaching and learning becomes more widespread, the need to make learning with computers more effective becomes more important. The accommodation of individual learning styles is often regarded as a way of increasing learning effectiveness. The idea that we can classify a learner and then employ methods and activities that match the way they prefer to learn is an attractive one. The main goal of this paper is to examine how software for teaching and learning (courseware) can accommodate differences in preferred learning style.

\section{What is a learning style?}

Before presenting some learning style classifications from the literature, it is important to clarify what we mean by the term 'learning style'.

Many learner attributes that can affect performance on a learning task have been identified (see Goodyear et al, 1991). They include: intelligence, prior knowledge of the subject matter or skill, motivation, level of anxiety, estimation of learning ability (the learner's self-concept), the amount of learner control offered, and preferred cognitive or learning style (these terms are often used interchangeably).

A learning style can be defined as the preference that an individual may have for processing 
information in a particular way when carrying out a learning activity. Learning styles involve the cognitive processes that are implicated in learning, and can be thought of as learning 'habits' that allow a learner to benefit more from some experiences than from others.

It is claimed that accommodation of a learner's preferred learning style is one of several factors that must be in place for effective learning to take place (for example, Corno and Snow, 1986; de Corte, 1990). If pedagogical activities accommodate different learning styles, it is argued that motivation will increase and that consequently learning will be more enjoyable, effective and efficient. Table 1 shows examples of the different ways in which a learner might approach a learning activity (Goodyear et al, 1991; Groat and Musson 1995). Note that each category represents a spectrum of possibilities rather than a polarized definition. For example, a learner may fall part of the way along the deep-surface spectrum, rather than being either wholly a deep learner or wholly a surface learner.

\begin{tabular}{|c|c|c|c|}
\hline $\begin{array}{l}\text { Field } \\
\text { dependence }\end{array}$ & 1 & Independence & $\begin{array}{l}\text { A global or an analytic orientation towards a subject. Tests } \\
\text { for this are often visual / perceptual. }\end{array}$ \\
\hline Meaningful & 1 & Rote & $\begin{array}{l}\text { The extent to which leaming is meaningful rather than a } \\
\text { memorization exercise. This is often related to perception of } \\
\text { reward. }\end{array}$ \\
\hline Dualistic & 1 & Relativistic & $\begin{array}{l}\text { Immature learners have a simplistic, dualistic approach, and } \\
\text { more mature learners take a more complex, relativistic } \\
\text { approach. }\end{array}$ \\
\hline Instrumental & 1 & $\begin{array}{l}\text { Leaming } \\
\text { achievement }\end{array}$ & $\begin{array}{l}\text { Concern with maximizing external rewards (e.g. marks) } \\
\text { rather than with learning for its own sake. }\end{array}$ \\
\hline $\begin{array}{l}\text { Cognitive } \\
\text { complexity }\end{array}$ & 1 & Simplicity & $\begin{array}{l}\text { The degree of differentiation or hierarchic integration of } \\
\text { cognitive structures. }\end{array}$ \\
\hline Reflectivity & 1 & Impulsivity & $\begin{array}{l}\text { The extent to which leamers approach tasks with either } \\
\text { speed or accuracy as their main objective. }\end{array}$ \\
\hline Risk-taking & 1 & Safety & $\begin{array}{l}\text { The degree to which learners are willing to take chances } \\
\text { when working towards a goal. }\end{array}$ \\
\hline Convergence & 1 & Divergence & $\begin{array}{l}\text { A tendency to converge towards or diverge away from the } \\
\text { 'obvious' when hypothesizing. }\end{array}$ \\
\hline Deep & 1 & Surfoce & $\begin{array}{l}\text { Deep learning involves active engagement with content; } \\
\text { surface learning concentrates more on surface form. }\end{array}$ \\
\hline
\end{tabular}

Table 1: Examples of leaming styles

\section{A review of learning style classifications}

Three main learning style classifications can be identified as having had some influence on the design of paper- and computer-based learning materials.

Holists and serialists

Pask (1976) classifies learners as either serialists or holists. Holists prefer to work 'top-down'. They try to build a conceptual framework for the subject matter they are learning, and try to locate elements of their learning within that framework. Detailed understanding of basic concepts is deferred until a later stage: they prefer to get hold of the 'big picture' first. Serialists prefer to work 'bottom up'. They prefer to learn one step at a time, acquiring a 
detailed understanding of basic concepts before gradually moving on to more complicated issues. Serialists are initially much less interested in the bigger picture than holists.

Pask claims that this classification is stable across the different tasks a learner might carry out (i.e. holists are always holists no matter what they are doing), and that there is a notable decrease in performance if learners are forced to adopt the non-preferred style of learning. However, the empirical basis for these claims is rather narrow. In addition, Pask generalized his findings from work on psycho-motor skills to cognitive tasks, and there is little evidence that this is the case.

Divergers, assimilators, convergers and accommodators

Kolb's Learning Style Inventory (LSI) measures an individual's relative emphases on two bi-polar approaches to learning: the abstract ('thinking') / concrete ('feeling') dimension, and the active ('doing') / reflective ('watching') dimension (Kolb, 1984). Kolb's claim is that every learner has aspects of each classification in his or her preferred learning style, and that these will vary between learners, with different emphases being placed on different factors. The LSI is a 9-item questionnaire where for each item respondents rank-order four words in a way that best describes their preferred learning style. The LSI places learners as relying primarily on dominant learning abilities in one of four categories: diverger, converger, assimilator and accommodator. In summary:

- divergers prefer concrete experiences and reflective observation;

- convergers prefer abstract conceptualization and active experimentation;

- assimilators prefer abstract conceptualization and reflective observation;

- accommodators prefer concrete experience and active experimentation.

Theorists, pragmatists, reflectors and activists

Honey and Mumford (Honey and Mumford, 1982) found that Kolb's descriptions and related inventory did not fit with their experiences, and were not meaningful to trainers and managers in commercial organizations. They developed a classification and a Learning Styles Questionnaire (LSQ) built around recognizable statements of lêarning behaviour, such as ' $I$ thrive on the challenge of tackling something new and different', and 'I am careful not to jump to conclusions too quickly'. Respondents are asked to check each statement as either correct (positive) or incorrect (negative). There are no right and wrong answers, and all responses have equal weight. The completed questionnaire is then analysed and the learner's preference for each of four learning styles is established.

At a general level, Honey and Mumford's four styles have much in common with Kolb's. However, their descriptions of learner characteristics and preferred learning activities are more detailed than and are different from the Kolb classification. In summary:

- theorists adapt and integrate observations into complex, logically sound theories - they think problems through step-by-step;

- pragmatists like to try out ideas, to see if they work in practice - they enjoy experimenting with new applications;

- reflectors like to stand back to ponder experiences and observe them from different perspectives; 
- activists involve themselves fully in new experiences - they are open-minded and enthusiastic about anything new.

The Honey and Mumford classification is the most well known among commercial trainers, and recently seems to be receiving a significant amount of attention in education. This is partly due to its accessibility and ease of practical application: a set of positive and negative learning activities is presented for each of the four learning styles. For example, it is claimed that activists learn best from activities where there are new experiences and opportunities from which to learn; they can become engrossed in short here-and-now activities; and there is a range of diverse activities. They learn least from activities where the task has non-obvious context or apparent purpose, the situation emphasizes emotions and feelings, activities are unstructured, and uncertainty and ambiguity are high.

\section{Tailoring learning for learning styles}

The idea that we can classify learners according to their preferred learning style, and can then match a set of complementary learning activities to that style is an attractive one. It has implications for the development of learning materials and learning activities, and also for decisions regarding the selection of learning opportunities.

From a teaching perspective, it should be possible to identify a set of activities that match each learning style, to match appropriate activities to an identified learning need, to determine the activities most likely to be effective for an individual with that learning need, and then to design resources accordingly. Similarly, it should be possible for a learner to review the learning resources and pedagogical activities associated with a particular learning opportunity such as a course or a module, and to assess how these relate to their preferred learning style. A course can then be selected or rejected depending on its match with a prospective learner's preferred way of learning.

A recent paper on this subject (Groat and Musson, 1995) discusses a possible mapping between learning styles and teaching strategies, and a subsequent translation into pedagogical methods. The latter includes decisions about the type of learning task presented, as well as techniques and strategies for providing feedback, examples, hints, reminders, and evaluations. Groat and Musson's analysis is based on the Honey and Mumford classification. It begins by mapping the four learning styles onto the bi-polar dimensions of two teaching strategies (concrete/abstract and safety/challenge). Pragmatists are in the concrete/safety sector; activists in the concrete/challenge sector; theorists in the abstract/challenge sector and reflectors in the abstract/safety sector. This mapping is then translated into the pedagogical methods that are seen as appropriate for each sector. For example, graphics are deemed to be better than text for presenting concrete examples, and 'clear structure' is better than 'freedom to explore' for learners who prefer safety to challenge. Thus, learners in the concrete/safety sector (pragmatists) are given graphical explanations and demonstrations, and are shown how to do a task before being given an opportunity to perform similar tasks.

\section{Key issues}

While it is clear that individuals can exhibit a preference for learning in a particular way, it is less clear that this preference is stable and reliable. Honey and Mumford claim that the LSQ has 
high validity with regard to classifying learners. Although there is some research attempting to test this claim (Allinson and Hayes, 1990, and Fung et al, 1993 are two examples), there is little conclusive evidence. A number of key issues must be addressed in this regard.

Are learning styles constant over time?

While it may be possible to classify a learner on one occasion, there is little evidence that the classification will apply the next time we encounter that learner. We can think of a number of internal and external factors that may affect a preference for one way of learning over another on any one occasion. Internal factors are considered under learner attributes (see below). External factors include the time available for learning (for example, having time to experiment and hypothesize versus a need to find out information quickly), the learning objective (for example, learning for learning's sake versus learning for job performance), and the nature of available learning resources (for example, the media employed, such as text, video, audio, graphics).

Are learning styles subject-dependent?

There is little evidence to suggest that a preference for learning one topic in a particular way will carry over to any other topic. It is not even clear that preferences are constant within a topic: a learner may prefer to learn different aspects of a topic in different ways.

How does preferred learning style interact with other learner attributes?

A number of learner attributes that might affect performance: intelligence, prior knowledge, motivation, anxiety levels, self-concept, and learner control. As a crude measure, we can imagine that each attribute will have a 'level' somewhere between 'none' and 'high' on any learning task. The attributes cannot be independent: the level of one must affect that of others. It should therefore be assumed that the attribute levels in play for any learning task will also affect learning-style preference.

Should learners always be able to learn in their preferred way?

Pask (1976) claimed to observe a decrease in performance if learners were 'forced' to learn in their non-preferred style. However, it may not always possible for learners to learn in their preferred way: the very nature of the subject matter or skill to be learned may dictate the most appropriate style of learning, and this may be incompatible with the preferred style. In addition, a learning-style preference may be largely down to habit. It is possible that helping learners to be more flexible and to employ different learning strategies where required is more appropriate than trying to accommodate individual preference.

Is it feasible to classify learners?

In addition to issues of validity and predictive value, there are practical issues regarding the classification of learners using a tool such as the LSQ. Even if a computer-based version of the tool is available, it is highly impractical to hope to classify anything other than a small number of learners. In higher-education teaching, where intakes can often run into the hundreds, classification of individual learners may simply not be feasible.

\section{Implications for courseware design}

It is clear that there are different styles of learning, even if a preference for any one style may not be stable and reliable. One way of making courseware more effective may be to ensure that it takes account of learning-style preference. If possible, this must be done in a 
way that addresses the issues raised above. In this section we present two courseware design solutions that demonstrate how courseware can accommodate preferred learning style. Each is illustrated by an example showing its practical application. The first solution follows on from traditional research into learning styles, and assumes that it is possible to classify learners in advance. The second addresses some of the issues identified above. Honey and.Mumford's classification is used for illustrative purposes in all examples.

\section{Designing for a known learning-style preference}

The first design solution assumes that it is possible to classify learners as having a preferred learning style in advance of their using the courseware. This could be done by having the learner use a tool such as the LSQ, either paper-based or computer-based. Alternatively, a learner profile could be entered in advance for each learner who will use the courseware, stating his or her preferred learning style as perceived by himself or herself or by tutors. Regardless of method, the assumption is that the learner's preferred style is known by the system.

Figure 1: Coursewore design solution where preferred learning style is known

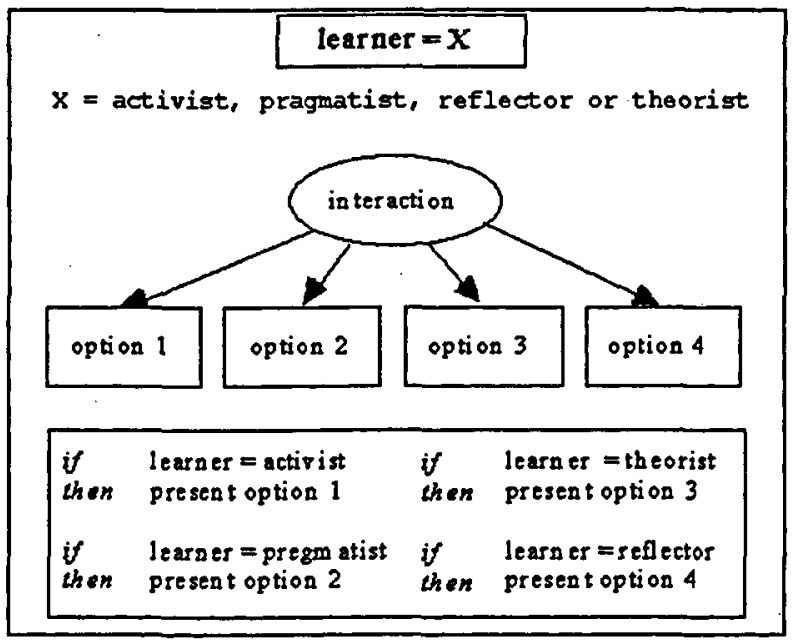

Figure 1 illustrates this design solution. The learner is classified in advance as either an activist, pragmatist, reflector or theorist. All subsequent interaction between the system and the learner, such as the presentation of material, any feedback given, remediation activities, and the amount of control offered to the learner, is influenced by the initial classification. At each stage of the interaction, there are four options, representing a different learning style classification. Each option prompts a different set of interactions, linked to the most appropriate methods and activities for that classification.

Figure 2 presents an example of the practical application of this solution. The courseware is required to provide feedback in response to a question that the learner has answered incorrectly. The feedback given will depend on the initial classification of the learner:

- if the learner is a pragmatist, the system will present some related examples and re-ask the initial question;

- if the learner is an activist, the system will give the correct answer straight away, and will move on; 
- if the learner is a theorist, the system will explain why the learner's answer is wrong in terms of the theoretical framework behind the topic, and will re-ask the question;

- if the learner is a reflector, the system will review the material already presented, asking him or her to think about specific points, and will then re-ask the original question.

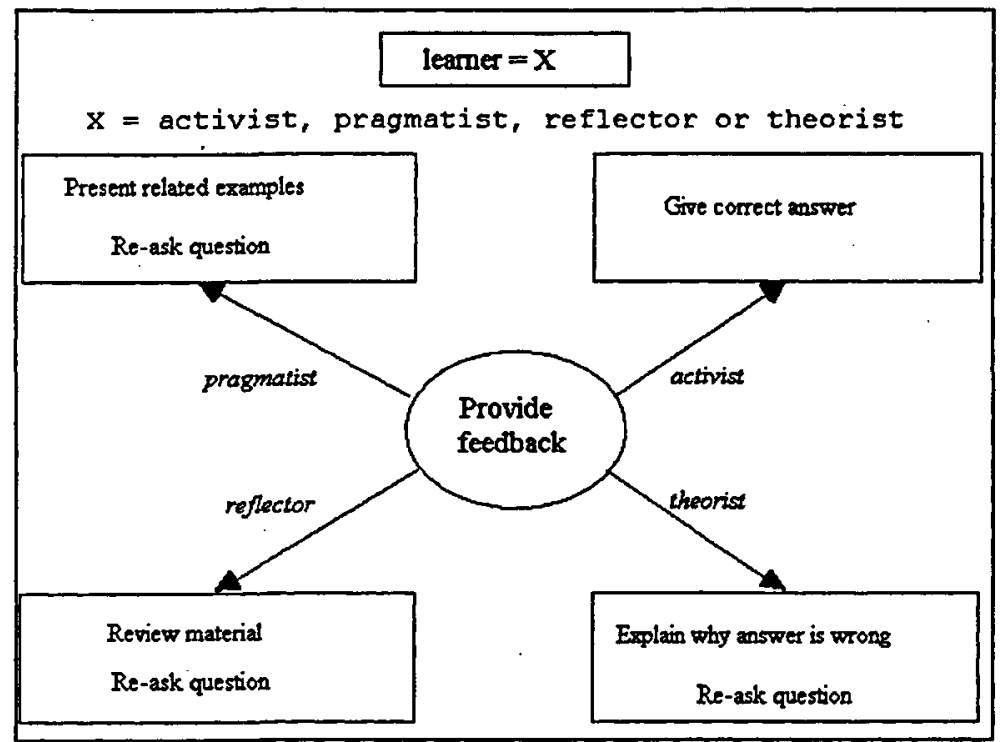

Figure 2: Courseware design example where preferred leaming style is

While this is a relatively simple example, it serves to show how a piece of courseware could accommodate individual preference for learning in a particular way, where the preferred learning style is known in advance. However, the solution does not address the issues raised above: the stability of learning styles over time, their interaction with other learner attributes, and their constancy across and within topics, as well as the feasibility of classifying learners in advance.

\section{Designing for an unknown learning-style preference}

The second design solution demonstrates how courseware can accommodate different learning styles without having an initial learner classification. This solution is attractive because it overcomes some of the problems discussed above. It acknowledges a preference for learning in different ways, while taking account of the fact that it may not be possible to classify learners in advance, and that preferences may not be stable and reliable. Figure 3 illustrates this design solution. For any interaction between the system and the learner, such as the presentation of material, provision of feedback, selection of remediation activities, and the amount of control offered to the learner, there are four options available. As with the first solution, each option corresponds to a set of activities that are appropriate for each of the four learning styles. However, there are two versions of this solution.

In the courseware-controlled version, the courseware would choose a default option, perhaps based on a heuristic such as 'always select the activist option because most people are activists'. Having presented the activities associated with the selected option, the 
Figure 3: Courseware design solution where the preferred learning style is not known

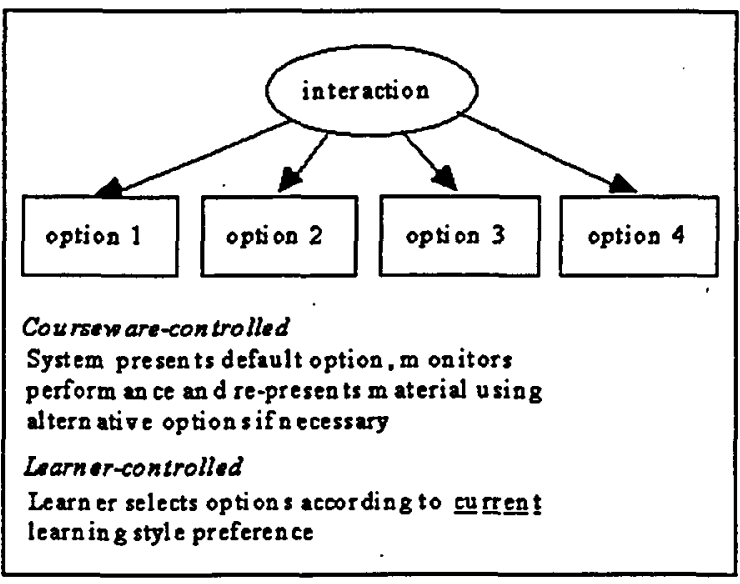

system would monitor learner performance, and could re-present the material by selecting one of the other options if necessary. This would require careful monitoring of userperformance, and, depending on the sophistication of the monitoring techniques employed, could easily come up against many of the problems faced by the learnermodelling community (see Self, 1988; Wenger, 1987). A simpler solution would be to adopt a 'wide-net' approach, presenting activities linked to all four options. This ensures that at least some will match the learner's preferred learning style. There may also be additional benefit from having learners tackle a topic in a number of ways. While not ideal, this is considerably better than the one-size-fits-all approach taken by most courseware.

In the learner-controlled version of the courseware, learners would select their preferred option. Any number and combination of the four options could be selected. This would allow learners to select learning activities according to their preferred learning style at that time, for that subject. It would also allow them to have access to the same material in a number of ways.

Figure 4: Courseware design example where the preferred learning style is not known

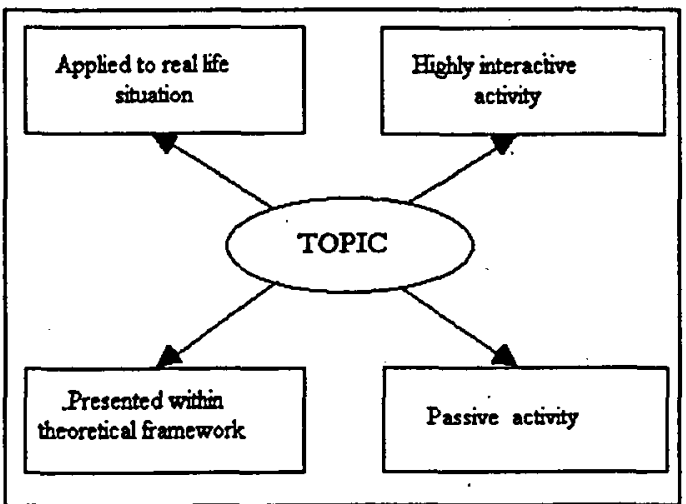

Figure 4 presents an example of the practical application of this design solution. The courseware has four ways of presenting a topic to the learner. Although the options have been developed with reference to suitable activities for the four identified learning styles, the learner's preferred style has not been established in advance. 
In the courseware-controlled version of this example, the courseware could initially present, as the default option, a highly interactive activity related to the topic. The learners' subsequent interaction with the courseware, such as their responses to questions, would be monitored. Any perceived under-performance would be remediated by re-presentation of the material using one of the other methods, such as applying the subject matter to a reallife situation. Monitoring and re-presentation could continue until all four activities had been presented. In the simpler implementation of this version, avoiding performance monitoring, all four activities would be presented to the learner in a pre-defined order (for example: present material within a theoretical framework, present passive activity, apply material to real life situation, and finish with highly interactive activity).

In the learner-controlled version of this example, the courseware would offer the learner four options regarding presentation of the topic. The learner would select the most suitable activity for his or her currently preferred way of learning. For example, one learner might feel that for him or her the topic under discussion would be more easily comprehended if presented within a theoretical framework. A different learner might prefer to see how the subject applies to real-life situations before taking on board more theoretical concepts.

\section{Conclusions}

In this paper we outlined a number of ways of classifying learners according to preferred learning style, and raised a number of issues regarding the feasibility of tailoring learning to accommodate learning styles. We presented two solutions that illustrate how courseware design can take into account individual preference for learning in a particular way. The first solution assumes that it is possible to classify a learner in advance. The classification determines the nature of any subsequent user-system interaction, such as the learning activities presented, the feedback given, methods used for remediation of errors and the amount of learner-control offered. The solution follows on from traditional research into learning styles in assuming that preference is stable over time, task, topic and so on. The second solution requires no advance classification of the learner. It provides an opportunity for learners to address a topic through a range of activities, appropriate for all learning styles, under the control of either the courseware or the learner. This solution makes no assumptions about the stability of learning-style preference. Both solutions are technically feasible for courseware developed using general purpose programming environments such as Visual Basic or $\mathrm{C}$ or relatively sophisticated authoring systems such as Authorware and IconAuthor (which allow global variables and which can accommodate branching and looping constructs).

However, the pedagogical feasibility of accommodating learning-style preference must also be considered, whether we are discussing the design of computer-based or paper-based learning materials. Although some speculative research has been carried out (Groat and Musson, 1995), there is not yet a sufficiently clear mapping between learning styles, teaching strategies and learning activities. With regard to computer-assisted learning in particular, it is unclear which specific characteristics of a learner interact with particular features of a piece of courseware, or how this interaction affects learning effectiveness. It is not sufficient to present learners with a range of suitable activities: there must be interaction between the learner and the courseware that actively engages the learner. in the learning process. Recent research on learning with interactive media suggests 12 
psychological processes (or learning functions) that must be engaged if learning is be effective (Shuell, 1992). Examples include prior knowledge, hypothesis generation, and motivation. Further research in this area could usefully focus on mapping learning styles, computer-based teaching strategies and a range of interactive learning activities that seek to stimulate relevant cognitive processes. This includes issues surrounding the appropriate use of multimedia resources, including video, audio, images and animation

I would argue that currently very little is known about the stability of learning styles, across a number of dimensions. Attempting to classify learners and to present only those activities which match their preferred style is therefore not a useful or worthwhile activity. However, a significant amount is known about the different ways in which any group of learners might prefer to learn. We should therefore at least aim to accommodate potential preference by presenting learners with a range of activities, even if at this stage we can only speculate about the most appropriate teaching strategies and pedagogical activities for each style.

\section{References}

Allinson, C.W. and Hayes, J. (1990), 'Validity of the learning style questionnaire', Psychological.Reports, 67, 859-66.

Corno, L. and Snow, R. (1986), 'Adapting teaching to individual differences among learners' in Wittrock, M. (ed), Handbook of Research on Teaching, New York: Macmillan, 605-29.

de Corte, E. (1990), 'Learning with new information technologies in schools: perspectives from the psychology of learning and instruction', Journal of Computer Assisted Learning, 6, 69-87.

Fung, Y. H., Ho, A.S.P. and Kwan, K.P. (1993), 'Reliability and validity of the Learning Styles Questionnaire', British Journal of Educational Technology, 24 (1), 12-21.

Goodyear, P., Njoo, M., Hijne, H. and van Berkum, J.J.A. (1991), 'Learning processes, learner attributes and simulations', Education and Computing, 6 (3/4), 263-304.

Groat, A. and Musson, T. (1995), 'Learning styles: individualizing computer-based learning environments', Association for Learning Technology Journal, 3 (2), 53-62.

Honey, P. and Mumford, A. (1982), The Manual of Learning Styles, Berkshire: Peter Honey.

Kolb, D.A. (1984), Experiential Learning: Experience as the Source of Learning and Development, Englewood Cliffs NJ: Prentice-Hall.

Pask, G. (1976), 'Styles and strategies of learning', British Journal of Educational Psychology, 46, 128-48.

Self, J.A. (1988), 'Bypassing the intractable problem of student modelling' in Proceedings of ITS'88, Montreal, Canada.

Shuell, T. J. (1992), 'Designing instructional computing systems for meaningful learning' in Winne, P.H. and Jones, M. (eds), Adaptive Learning Environments: Foundations and Frontiers, New York: Springer Verlag.

Wenger, E. (1987), Artificial Intelligence and Tutoring Systems: Computational and Cognitive Approaches to the Communication of Knowledge, Los Altos, CA: Morgan Kaufmann. 